\title{
O NAFTA (North American Free Trade Agreement) e algumas consequências socioeconômicas para o México: o caso das maquiladoras ${ }^{38}$
}

\author{
Katiuscia Moreno Galhera Espósito ${ }^{39}$
}

\section{Resumo}

A partir da década de 1970, a internacionalização das empresas trouxe para os governos nacionais novas questões como o emprego formal em multinacionais (MNC), mecanismos contábeis cada vez mais sofisticados utilizados pelas MNCs (como o transfer pricing) e a terceirização (outsourcing), dentre outros. Cada Estado responde de forma diferente aos desafios da "globalização": se por vezes buscam combater a precarização do trabalho - como é o caso da maior parte dos países na União Europeia, por outras chegam a mudar sua legislação para flexibilizar as condições de trabalho e atrair Investimento Externo Direto (IED) - como no estudo de caso proposto neste artigo. Este trabalho visa a analisar as condições do mercado de trabalho no México, após as mudanças ocorridas no país para propiciar a entrada de grandes investidores, quando da assinatura do North American Free Trade Agreement (Nafta). Mais especificamente, o exame será realizado nas maquiladoras no país. Partiremos da hipótese inicial de que a atual situação mexicana é resultado da conjugação de seus fatores internos e dos acontecimentos no sistema internacional. Ao fim, apontam-se algumas consequências socioeconômicas do acordo de livre comércio, tomando como exemplo o caso Nafta-México. Espera-se que a análise de um país que apresenta várias características semelhantes às condições socioeconômicas brasileiras propicie uma comparação com o Brasil, com vistas a facilitar futuros estudos e tomadas de decisão.

Palavras-chave: Globalização, Desenvolvimento, Acordo de Livre-comércio.

\footnotetext{
38 O presente artigo está em parte baseado em minha dissertação de mestrado, intitulada "Transnacionalização das relações de trabalho: o caso da maquila estadunidense Johnson Controls (plantas FINSA e Interiores) e o papel da Federação Internacional de Trabalhadores das Indústrias Metalúrgicas (Fitim)", defendida em 2012 junto ao Programa San Tiago Dantas de Pós-Graduação em Relações Internacionais (PUCSP / Unesp / Unicamp).

${ }^{39}$ Doutoranda em Ciência Política/UNICAMP.
}

\section{Introdução}

A crise do Estado-nação passa por diferentes processos, sendo a maior parte deles ligada aos aspectos econômicos das mudanças ocorridas no sistema internacional. Essas mudanças, conjugadas com as dinâmicas internas do próprio Estado, trazem impactos para todas as camadas da população. No caso mexicano, argumentaremos que, para além das transformações ocorridas no âmbito do governo, a assinatura de um tratado de livre comércio com os EUA e o Canadá é um dos fatores determinantes das condições socioeconômicas do país. Em outras palavras, as dinâmicas que ocorrem dentro $e$ fora das fronteiras nacionais definem a vida de milhões de mexicanos.

Partimos da hipótese inicial de que a assinatura do Nafta, pelo seu formato e conteúdo, apesar de trazer benefícios para a economia mexicana, também apresenta múltiplas falhas como modelo de desenvolvimento (de liberalização e exportação voltada para o bloco) para o seu mercado de trabalho e, especialmente, para a região das maquiladoras ${ }^{40}$. Nosso estudo de caso se foca nas relações laborais de uma maquiladora, por terem as maquilas proliferado principalmente após a assinatura do acordo e retratarem de maneira fidedigna os dois quadros apontados: o de influência da famigerada e confusa "globalização" e o quadro geral do mercado de trabalho mexicano.

A opção pelo estudo de caso mexicano, e não brasileiro, foi devido às características comuns entre os dois países (grandes populações e dimensões territoriais, o abandono do modelo de desenvolvimento baseado em substituição de

\footnotetext{
40 A região das maquiladoras se assemelha com as zonas francas, e.g. a Zona Franca de Manaus. Nas maquilas, tendo em vista as características das zonas francas, a mão-de-obra é menos bem remunerada e as condições de trabalho costumam ser insalubres.
} 
importações, história que remonta ao passado colonial); contudo, suas estratégias de desenvolvimento, que definiram suas posições no sistema internacional, foram completamente distintas. Com a análise dos resultados de tais estratégias, acreditamos contribuir com estudos que consubstanciem futuras decisões brasileiras para o desenvolvimento.

Enquanto o México voltou seu modelo de desenvolvimento para a liberalização comercial, atração de investimento externo e atendimento aos mercados do Nafta, o Brasil não passou por tal experiência, buscando atrair investimentos para o suprimento do mercado interno e a diversificação da pauta exportadora através de seus vizinhos continentais, principalmente via Mercado Comum do Sul, o Mercosul, derivado de tratado anterior ao que criou o Nafta.

$\mathrm{O}$ artigo está dividido em duas partes, além da introdução e conclusão. Na primeira, procuramos demonstrar, através de dados oferecidos pelo Banco Mundial, o quão impactante foi para a economia do México sua entrada no Nafta. Para tanto, analisamos a variação do Produto Interno Bruto (PIB) do país, bem como seu PIB per capita, a participação das importações e exportações no PIB e os fluxos de IED invertidos naquele Estado. $\mathrm{Na}$ segunda parte, abordamos as consequências do Nafta para o mercado de trabalho da região das maquiladoras. Por último, tecemos nossas considerações finais.

\section{O Nafta (North American Free Trade Agreement)}

\subsection{Características e números}

Em junho de 1990, os presidentes do México e dos Estados Unidos iniciaram as tratativas relacionadas a um tratado de livre comércio. O mecanismo intitulado fast track $^{41}$ foi aprovado pelo Congresso estadunidense em 1991 (Vega apud Toledo [2001?], 1), quando também se iniciaram as negociações

\footnotetext{
41 De acordo com Thomaz (2012, 32-33): "O processo de liberalização dos EUA tem relação direta com a aprovação, em 1974, do fast track, conhecido, desde 2002, como Trade Promotion Authority (TPA). Através desse mecanismo, o Congresso concede ao Presidente autoridade para negociar acordos comerciais sem a interferência do Legislativo para emenda, ou seja, o Congresso deve apenas aprovar ou vetar o acordo. O fast track ficou em vigor de 1974 a 1994, sendo novamente acionado em 2002, estando vigente até 2007, a fim de facilitar as negociações comerciais (em fase de elaboração)".
}

trinacionais (entre México, EUA e Canadá). Em agosto de 1992, os acordos foram concluídos e, em fevereiro de 1993, foram decididos os adendos relacionados ao meio ambiente e às questões laborais (idem [2001?], 1).

Em $1^{\circ}$ de janeiro de 1994, passou a vigorar formalmente o acordo, conhecido como Nafta. Trata-se da maior área de livre comércio do mundo, que atingiu 450 milhões de pessoas e movimentou US\$ 17 trilhões em bens e serviços desde o seu surgimento até 2011 (United States Trade Representative, 2011).

Quanto ao México, os números dão a dimensão de seu impacto no país: através dos Investimentos Externos Diretos (IED) se percebe mais nitidamente a presença do Nafta. Os IEDs entraram em um ritmo de crescimento contínuo até 2001, ano em que o IED no México chegou a aproximadamente US\$ 30 bilhões, segundo dados do Banco Mundial (ver tabela 1 a seguir).

O IED dos Estados Unidos no bloco foi de US\$ 357,7 bilhões em 2009 (o que equivale a um aumento de 8,8\% em comparação a 2008), principalmente para as áreas de manufaturas, seguros e mineração, de acordo com os últimos dados oficiais disponíveis no site do governo estadunidense (United States Representative, 2011). Do início do tratado até 2002 foram aproximadamente US\$ 7 bilhões investidos, contra US\$ 1,9 bilhão no período de 1984 a 1993 (Sánchez apud Santos 2007, 153): a comparação entre ambos os períodos (1984-1993 e 1994-2002) nos permite visualizar o enorme montante investido e, consequentemente, recebido pelos países em forma de investimentos que mais tarde se traduzirá, dentre outros, em linhas de montagem no formato das maquilas.

Foram os IEDs estadunidenses que propiciaram o surgimento de muitas das empresas maquiladoras no México. A partir de 1965, o governo mexicano decidiu implantar um programa industrial orientado para a exportação, permitindo que os EUA, construíssem montadoras ao longo da fronteira entre os dois países (Kay 2011, 50). Pouco depois, as maquilas passaram a penetrar também em outras regiões do México, como no centro do país e até no sul, em uma espécie de migração industrial expansiva, como pode ser observado no mapa abaixo, onde a distribuição dos empregos segue o curso geográfico mexicano. 
Tabela 1 - MÉXICO: DADOS SOCIOECONÔMICOS - DE 1993 A 2010

\begin{tabular}{|c|c|c|c|c|c|c|c|c|c|}
\hline Ano & 1993 & 1994 & 1995 & 1996 & 1997 & 1998 & 1999 & 2000 & 2001 \\
\hline PIB (em US\$ bilhões) & 403,195 & 421,725 & 286,698 & 332,908 & 401,48 & 421,215 & 481,202 & 581,426 & 622,093 \\
\hline PIB per capita (US\$) & $4.524,71$ & $4.650,11$ & $3.107,07$ & $3.546,93$ & $4.206,56$ & $4.342,33$ & $4.884,63$ & $5.816,61$ & $6.139,30$ \\
\hline Import + Export/ PIB & $29,60 \%$ & $33,90 \%$ & $53,70 \%$ & $56,50 \%$ & $55,70 \%$ & $58,50 \%$ & $58,70 \%$ & $59,50 \%$ & $53,30 \%$ \\
\hline IED líquido (em US\$ bi) & 4,389 & 10,972 & 9,526 & 9,185 & 12,829 & 12,756 & 13,879 & 18,109 & 29,848 \\
\hline Pobreza & & $52,40 \%$ & & $69,00 \%$ & & $63,70 \%$ & & $53,60 \%$ & \\
\hline Ano & 2002 & 2003 & 2004 & 2005 & 2006 & 2007 & 2008 & 2009 & 2010 \\
\hline PIB (em US\$ bilhões) & 649,076 & 700,325 & 759,777 & 848,947 & 952,276 & $1.035,93$ & $1.096,18$ & 882,787 & $1.039,66$ \\
\hline PIB per capita (US\$) & $6.324,17$ & $6.740,21$ & $7.223,87$ & $7.972,55$ & $8.830,84$ & $9.484,73$ & $9.893,41$ & $7.875,82$ & $9.132,81$ \\
\hline Import + Export/ PIB & $51,40 \%$ & $48,60 \%$ & $51,40 \%$ & $52,10 \%$ & $53,90 \%$ & $54,30 \%$ & $55,60 \%$ & $65,80 \%$ & \\
\hline IED líquido (em US\$ bi) & 23,783 & 16,243 & 24,8 & 24,122 & 20,052 & 29,734 & 26,295 & 15,334 & 18,679 \\
\hline Pobreza & $50,00 \%$ & & $47,20 \%$ & $47,00 \%$ & $42,60 \%$ & & $47,40 \%$ & & \\
\hline
\end{tabular}

Fonte: Banco Mundial. Disponível em: <http://www.worldbank.org/en/country/mexico>. Acesso em 4 abr. 2012

\begin{tabular}{|c|c|}
\hline LEGENDA & \\
\hline PIB (em US\$ bilhões) & Produto Interno Bruto \\
\hline PIB per capita (US\$) & PIB dividido pela população \\
\hline Import + Export/ PIB & Participação das importações e exportações no PIB \\
\hline IED líquido (em US\$ bi) $)^{42}$ & Investimento Externo Direto \\
\hline Pobreza & $\%$ de pessoas que vivem abaixo da linha da pobreza \\
\hline
\end{tabular}

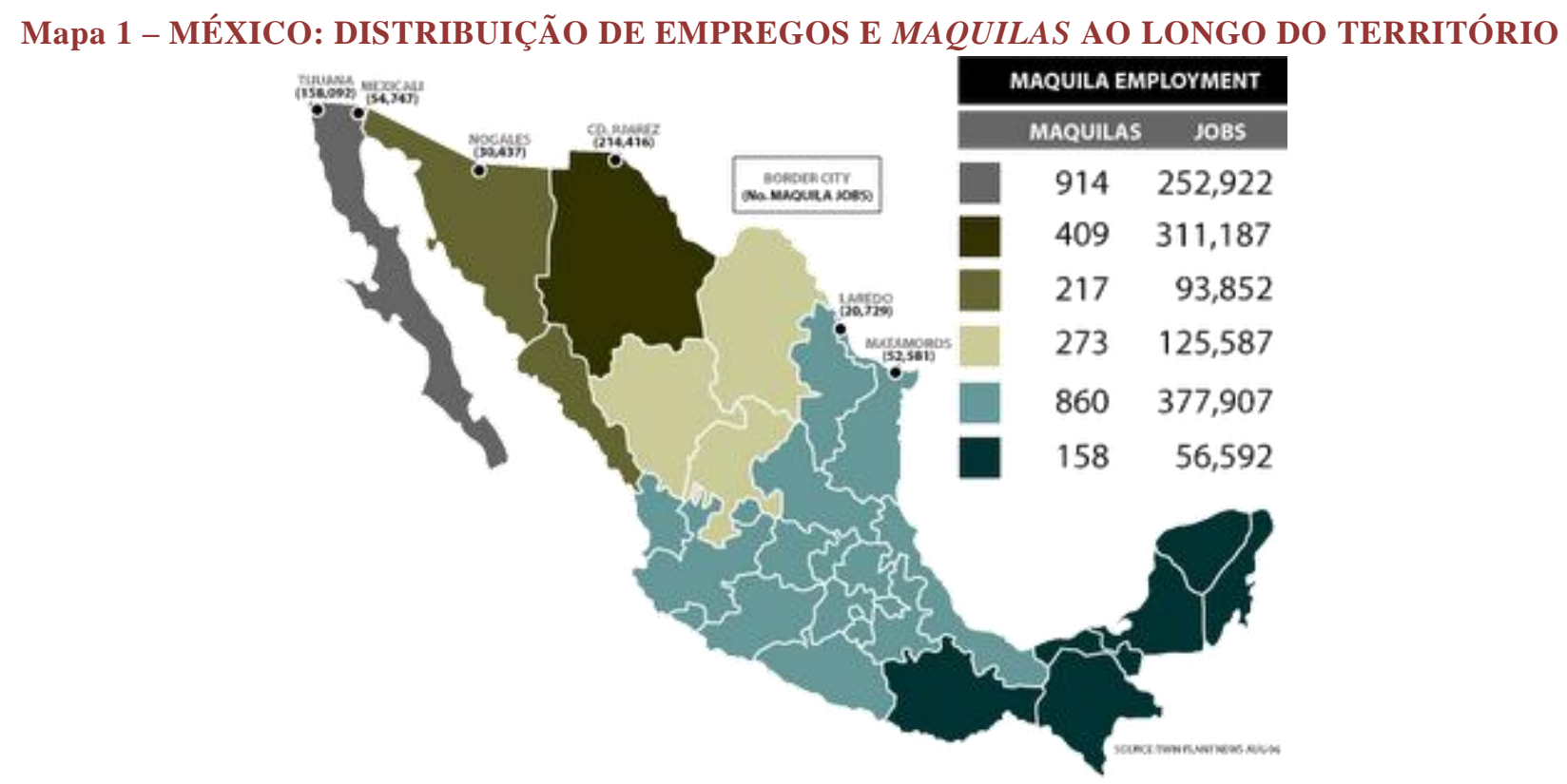

Fonte: Futuribles México. Disponível em: <http://futuriblesmexico.blogspot.com.br/2009/11/mapa-de-la-maquilaen-mexico.html>. Acesso em 7 de maio de 2012

\footnotetext{
${ }^{42}$ De acordo com o site do Banco Mundial (2012), IED líquido é o equivalente a "entradas líquidas de investimento para aquisição de participação em uma gestão duradoura (10\% ou mais do capital volante) em uma empresa que opera em uma economia diferente da economia do investidor. É a soma de capital próprio, reinvestimento dos lucros, outros capitais de longo prazo e capital de curto prazo, como mostrado na balança de pagamentos. Os dados obtidos mostram as entradas líquidas (entradas de novos investimentos menos desinvestimentos) nos relatórios de investidores estrangeiros. Os dados são em dólares correntes dos EUA" (tradução nossa). Disponível em:

<http://data.worldbank.org/indicator/BX.KLT.DINV.CD.WD/countries/MX?display=graph>. Acesso em 16 ago. 2012.
} 
De acordo com o Banco Nacional de Comércio Exterior do México (apud Wise e Cypher 2007, 125), em 2005, “[...] nas mais de três centenas de empresas maquiladoras que se aglomeram ao longo da fronteira Estados Unidos-México, são empregados mais de 1,2 milhão de trabalhadores, os quais geraram $55 \%$ das exportações de manufaturados do país em 2004" (tradução nossa). Aponta-se que:

\begin{abstract}
A região da maquila funciona como zona franca, sem qualquer conexão com a cadeia produtiva do parque industrial mexicano. Autoveículos e autopeças figuram entre os variados produtos que por ali transitam. As três grandes montadoras norteamericanas possuem instalações locais, o que se dá igualmente com a Honda, a Nissan e a Volkswagen. Tais instalações nada têm a ver com as plantas das mesmas EMs [empresas multinacionais] localizadas nas outras regiões do país. (Gorender 1997, 339-340).
\end{abstract}

No caso da indústria automotiva mexicana, a desvalorização da moeda nacional (o peso) ocorrida na crise de $1994^{43}$, somada à assinatura do acordo, fez com que as exportações do país superassem o mercado doméstico. Se antes de 1994 o México aplicava $20 \%$ de tarifa a todos os veículos importados (sendo 9,2\% aplicados pelo Canadá e 2,5\% pelos EUA), por volta de 2004 essa tarifa chegava a $10 \%$ para as importações de veículos, e a não taxação de produtos se aplicava a $90 \%$ do comércio entre os três países (Federação Internacional de Trabalhadores das Indústrias Metalúrgicas [2005?], 35). Nas maquiladoras, a isenção de tarifas sobre os produtos fabricados seguiu uma progressão simples, até sua total extinção: a diminuição das taxações sobre os produtos fabricados nessas áreas foi fixada em 5\% ao ano, passando de 55\% em 1994 para $100 \%$ em 2003, data da completa isenção de tarifas sobre os produtos maquilados.

\footnotetext{
${ }^{43}$ De acordo com Belluzzo (1995), a crise mexicana de 1994 se deveu à "imprudência de uma persistente valorização da taxa real de câmbio, $[\ldots]$ déficit em conta corrente, [...] [acúmulo de] passivos em moeda estrangeira, no setor público e na esfera privada, [...] mega desvalorização, [impossibilidade de] ajuste fiscal, [...] excessiva dependência do financiamento externo, $[\ldots]$ programas de desinflação rápida com âncora (e valorização) cambial e abertura da economia". Segundo Núñez e Ocaña $(1999,4)$, a partir de 1994 e por todo o ano de 1995 a crise do câmbio se transforma em crise financeira e "se apodera de toda la estructura productiva con su larga secuela de desempleo, agudización de la pérdida en la capacidad adquisitiva $y$ en general, [generando] un proceso de empobrecimiento generalizado para la mayoría de la población"
}

A porcentagem das importações e exportações no PIB do México é ilustrativa do aumento de sua participação no comércio regional: se, em 1994, $33,9 \%$ do PIB correspondiam às importações e exportações do país, em 1995 essa fatia equivalia a $53,7 \%$. O nível mais alto de participação das importações e exportações do país no PIB foi em 2009 (65,8\%), também segundo dados do Banco Mundial, conforme a tabela 1 .

Em $1^{\circ}$ de janeiro de 2008, todos os resquícios de restrições e tarifas sobre os produtos comercializados entre os países foram eliminados. Para o Nafta, foi o ano do livre comércio em seu sentido mais pleno (United States Trade Representative, 2011). Analisaremos, a seguir, se o acordo trouxe benefícios ao México.

\section{Consequências do Nafta para o México}

A partir do início da vigência do acordo, o fluxo de IED invertido no México, bem como o seu PIB, aumentaram, como demonstram os dados do Banco Mundial constantes da tabela 1. Contudo, o mesmo ocorreu com as taxas de pobreza. Como argumentam Royo, Dormond e Arias (2005, 147), o aumento do PIB caminha junto com o aumento da pobreza no México. Se em 1992 (dois anos antes do acordo) $53,1 \%$ dos mexicanos eram considerados pobres pelo Banco Mundial, em 1996 (dois anos após a assinatura do acordo) uma parcela espantosa de $69 \%$ da população vivia em condições de pobreza (ver tabela 1 acima).

É possível argumentar que o México enfrentou uma aguda crise em 1994. Os dados indicam, entretanto, que, se em 1998 era de 63,7\% o percentual de pobres mexicanos, em 2008 esse patamar continuava alto: $47,4 \%$. Esse período de tempo, que seria suficiente para a recuperação de uma crise pontual, demonstra que o acordo não trouxe à população benefícios no curto prazo, ou benefícios substantivos de longo prazo, já que se manteve uma taxa alta de pessoas consideradas pobres (mesmo com a diminuição do percentual).

Além disso, ainda que o acordo entre Estados Unidos, Canadá e México tenha efetivamente aumentado a circulação de bens e serviços, ainda não existe a liberdade de trânsito de pessoas nos países que dele participam (salvo profissionais e executivos qualificados), como prevê a constituição da União Europeia, por exemplo. 
No documento relativo à cooperação em assuntos de trabalho, o North American Agreement on Labour Cooperation (NAALC), está prevista a melhoria das condições de trabalho e nível de vida em todos os territórios (Estados Unidos; Canadá; México, 2011 [1994]). Entretanto, "diferentemente dos direitos de investidor e de propriedade intelectual, padrões trabalhistas e ambientais não se encontram [efetivamente] presentes no Nafta, o que significa que a violação desses não invalida o acordo, nem justifica uma ação contra um dos signatários" (Gacek apud Friedmann 2008, 56).

Quanto às melhorias nas condições de trabalho nos países:

[...] são princípios orientadores que as Partes se comprometem a promover, sujeitos às leis internas de cada País, mas que não estabelecem padrões mínimos comuns para essas leis internas. Os princípios indicam grandes áreas de interesse nas quais as Partes tenham desenvolvido, cada uma de sua forma, suas próprias leis, regulações, procedimentos e práticas que protegem os direitos e interesses de suas respectivas forças de trabalho. (Estados Unidos; Canadá, México 2011, grifo nosso, tradução nossa).

Em outras palavras, apesar de o acordo prever itens trabalhistas avançados (como a proteção aos trabalhadores migrantes), a legislação nacional tem primazia sobre o acordo, anulando-o em quaisquer casos de discordância com as leis internas dos países. A liberdade sindical (Convenção 87 da OIT), por exemplo, nunca foi ratificada pelos Estados Unidos. Entretanto, são previstos no acordo liberdade sindical, direito de negociação coletiva e direito à greve ${ }^{44}$ :

O acordo do Nafta relativo ao trabalho tem sido altamente criticado pela sua incapacidade de assegurar o enforcement do governo sobre as leis trabalhistas nacionais. (Human Rights Watch apud Cook 2004, 3, tradução nossa).

Os acordos de comércio com disposições relativas ao trabalho, como o Nafta, obrigam os governos a reforçar suas legislações internas, no lugar de reformar suas leis para alcançar

\footnotetext{
44 Estão previstos no acordo: "freedom of association and protection of the right to organize; the right to bargain collectively; the right to strike; prohibition of forced labor; labor protections for children and young persons; minimum employment standards; elimination of employment discrimination; equal pay for women and men; prevention of occupational injuries and illnesses; compensation in cases of occupational injuries and illnesses; protection of migrant workers" (México, Estados Unidos, Canadá 2011, anexo I).
}

patamares mais altos. Mesmo com o NAALC exigindo um comprometimento dos governos em relação aos direitos trabalhistas, fornecendo, portanto, a base para a alegação de que as leis existentes talvez não sejam eficazes, não existe disposição para um monitoramento contínuo do cumprimento dos princípios do acordo pelos membros do governo. Ao invés disso, o sistema [...] funciona através de denúncias. Isso significa que, a menos que sindicatos, ONGs, ou outros grupos de defensores dos direitos busquem resolver casos através do NAALC, nenhuma pressão é exercida sobre o governo do país transgressor. (idem 2004, 4, tradução nossa).

O acordo também não cita nenhum tribunal supranacional para resolução de conflitos:

\begin{abstract}
Há um $\mathrm{NAO}^{45}$ em cada país-membro com o papel de receber as queixas apresentadas, com a característica que o indivíduo, grupo ou entidade(s) reclamante(s) não pode(m) apresentar queixas sobre a violação de direitos em seu próprio país. Somente pode se referir a violações ocorridas nos outros dois. Um dos encaminhamentos adotados pelos NAOs é o de promover consultas junto a instituições do país acusado. Os NAOs do Canadá e EUA têm promovido audiências públicas no trato das queixas, mas o escritório do México não.

O movimento sindical dos três países tem tentado utilizar os procedimentos e instrumentos de avaliação do NAALC [North American Agreement on Labor Cooperation, acima citado] para enfrentar o comportamento de certas EMNs [empresas multinacionais] após a entrada em vigor do Nafta, mas afirmam que os resultados são pobres devido ao caráter voluntário do acordo e a complexidade de seu funcionamento. (Jakobsen 2009, 76).
\end{abstract}

Tamara Kay (2011, passim) destaca a possibilidade de cooperação e formação de uma identidade norteamericana (via mecanismos de governança propiciados pelos NAOs e pelo NAALC) entre os sindicatos dos três países. De fato, numerosos casos referentes à violação de direitos no México têm sido reportados junto ao tribunal, sendo que "a maioria dos casos tem questionado a ausência de votações secretas nas eleições representativas e a imparcialidade dos conselhos de trabalho" (Cook 2004, 11, tradução nossa). Apesar de não discordarmos de Kay, devemos apontar que esses mecanismos, justamente por reforçarem o estado de

\footnotetext{
${ }^{45} \mathrm{O}$ "National Administrative Office" (NAO) é um dos braços da Comissão para Cooperação Trabalhista. Os outros dois são (i) um Comitê Avaliador e (ii) os Painéis Arbitrais. Os NAOs são os organismos responsáveis por receber reclamações trabalhistas em cada território nacional.
} 
coisas nas relações laborais dos países, não melhoraram as condições de trabalho dos mexicanos, já que inúmeros problemas, como os contratos de protección ${ }^{46}$ e os sindicatos de papel ${ }^{47}$, foram aprofundados quando da atuação de empresas pós-acordo.

Com relação aos números das Balanças Comerciais dos países, devemos apontar que o notável aumento da participação das importações e exportações no PIB do México - de 33,9\% em 1994 para 53,7\% do PIB em 1995 - demonstra claramente que, a partir de então, houve um aprofundamento da dependência do país em relação às trocas comerciais no Nafta, especialmente com os EUA. Com efeito, a produção da indústria maquiladora se orienta quase integralmente pelo mercado dos Estados Unidos (Salas [2003?], 3) e há evidências de que, pelo menos no período entre 1994 e 2000, os empregos criados nas maquilas pagavam $52 \%$ menos do que os outros postos de trabalho (Cypher apud Wise e Cypher 2007, 126). Ademais,

[...] metade dos produtos dos Estados Unidos exportados para o México jamais entra no mercado mexicano, é simplesmente transferida de uma filial de uma firma norte-americana para outra, atravessando a fronteira para fazer uso de mão-de-obra mais barata e livrar-se de regulamentos ambientais e trabalhistas, retornando depois aos Estados Unidos como importações. (Chomsky 1997, 265, grifo do autor).

Portanto, podemos citar o transfer price, as transações intrafirma, o acordo de livre-comércio e o emprego de mão-de-obra barata como alguns dentre as centenas de itens que diminuem sensivelmente o custo dos produtos acabados confeccionados no México.

\footnotetext{
${ }^{46}$ Contratos de protección patronal são pseudo contratos firmados pelas empresas de advocacia ou outros grupos, como os sindicatos de papel. Na realidade, esses acordos não buscam representar efetivamente os trabalhadores, tendo em vista que estes não estão diretamente envolvidos no processo de escolha dos atores que os assinam. Uma vez assinado, o contrato coletivo de trabalho é registrado junto à JCA, e o empregador não pode firmar contrato com outro sindicato imediatamente, pelo princípio de titularidad.

${ }^{47}$ Sindicatos de papel ou fantasmas são, como o próprio nome sugere, instituições legais que exercem suas funções como representantes dos trabalhadores apenas no papel. Na prática, se aproveitam de figuras igualmente legais, como o princípio de titularidad, para se estabelecer em dada empresa e receber contribuições sindicais sem qualquer esforço e sem gerar benfeitorias efetivas aos trabalhadores. Tais sindicatos podem surgir antes mesmo da contratação do primeiro empregado, frequentemente em parceria com o próprio empresariado, sem qualquer transgressão aparente da lei.
}

Para Wise e Cypher (2007, 120-121), as maquilas funcionam como exportação indireta de mão de obra barata e não especializada para os Estados Unidos, com a vantagem, para os estadunidenses, de serem um mecanismo que não infla seu sistema previdenciário. Afinal, "passada mais de uma década do nascimento do Nafta e duas décadas de reformas para o mercado, não há nenhum indício de que o país possa ingressar no 'primeiro mundo"'. (Santos 2007, 151, grifo nosso).

Como tentamos demonstrar, o acordo de livre comércio nos moldes do Nafta não foi benéfico para o México e, portanto, também não beneficiou os trabalhadores mexicanos. Dessas duas assertivas podemos inferir uma terceira, que é o desmantelamento da capacidade de atuação dos sindicatos (ainda que no caso do México o quadro sindical seja mais complicado do que parece, como veremos adiante), pois, se o nível de pobreza aumentou no país, provavelmente os sindicatos não têm desenvolvido propostas efetivas para o aumento dos níveis salariais no país. O desmantelamento parcial da capacidade de atuação dos sindicatos deriva, conforme demonstramos, das novas questões da era pósfordista/de acumulação flexível:

O influente sistema de produção Toyota [ocorrido na era pós-fordista], com seus mecanismos de entrega pontuais, tem sido adotado por todos os outros fabricantes de automóveis e por empresas de outros ramos [...]

As consequências disso para os trabalhadores e administrações locais têm sido graves. O emprego com baixo salário, somado a condições de vida miseráveis, no setor das maquiladoras do México [...] ocupa o lugar do trabalho bem remunerado e relativamente seguro que constitui a base das condições de vida dignas. $O$ fechamento de plantas destrói a base de recolhimento fiscal local em algumas áreas, enquanto outras comunidades destroem o erário público em seu esforço por atrair ou manter investimentos. As principais beneficiadas dessa situação têm sido as multinacionais [...].

A tendência de externalização tem conduzido à perda de postos de trabalho sindical, de densidade sindical e de poder aquisitivo. (Federação Internacional de Trabalhadores das Indústrias Metalúrgicas 2004, 14-18, tradução nossa).

\section{Considerações finais}

O presente artigo buscou levantar, a partir de dados estatísticos e de revisão bibliográfica, as consequências socioeconômicas da assinatura do Nafta para o México. Especificamente, buscamos 
apontar as relações laborais nas maquiladoras, que proliferaram após a assinatura do acordo. Também buscamos conjugar os fatores internos $\mathrm{e}$ internacionais que determinam a situação mexicana depois de 1994.

Dadas as características comuns entre México e Brasil e tendo em vista o fato de que o segundo não

possui acordo comercial nos moldes do Nafta e nem tampouco realizou estratégia de desenvolvimento (liberal-exportadora voltada para o bloco regional), objetivamos tomar o exemplo mexicano (de sucesso ou fracasso) como modelo a ser seguido, ou não, pelo Brasil.

Como vimos a despeito do substancial aumento dos fluxos de IED para o México, o Nafta não parece trazer apenas benefícios ao país. Os indicadores de aumento substancial da pobreza mexicanos, divulgados pelo Banco Mundial, nos permitem arriscar essa assertiva.

Também demonstramos que nossa hipótese inicial estava correta: a situação socioeconômica do México é resultado da conjugação de fatores internos e externos que afetam a base da população. Portanto, os condicionantes do atual estado do mercado de trabalho podem ser encontrados dentro das fronteiras nacionais $e$ na configuração econômica do sistema internacional, em um processo contínuo de co-construção de quadros sociais, políticos e econômicos.

Sem a pretensão de esgotar o assunto podemos afirmar, a partir dos estudos realizados no breve estudo de caso proposto neste artigo, que o atual modelo mexicano de desenvolvimento não é adequado para o Brasil.

\section{Referências}

Chomsky, N. Consentimento sem consentimento: a teoria e a prática da democracia. Estudos avançados, v. 11, n. 29, Jan/Abr, 1997, São Paulo.

Cook, M. L. 'International labor standards and domestic labor advocates: unions, labor reform, and workers' rights in Latin America (draft)', in Conference on Transnational Labor Contention Program for the Study of Contentious Politics, Nova Iorque, 9-11/abr/2004. Anais... Nova Iorque: New York State School of Industrial and Labor Relations Cornell University Ithaca, 2004, p.1-21.

Estados Unidos; Canadá; México. Câmara dos Deputados. North American Agreement on Labor Cooperation between the government of the United States of America, the government of Canada, and the government of the United Mexican States, 2011 [1994]. Disponível em: http://www.hrsdc.gc.ca/eng/lp/spila/ialc/02naalc.shtml. Acesso em 26/mai/2012.

Federação Internacional de Trabalhadores das Indústrias Metalúrgicas. Metalworkers and the Free Trade of Americas. Genebra, 2004?. Disponível em http://www.imfmetal.org/files/FTAA-REPORT-2002-Englishq.pdf. Acesso em 12/mai/2012.

Friedmann, G. C. Globalização capitalista, desregulamentação dos direitos do trabalho e cláusulas sociais nos acordos comerciais internacionais. Universidade Estadual de Campinas. 2008. Dissertação (Mestrado em Relações Internacionais).

Gorender, J. Globalização, tecnologia e relações de trabalho. Estudos avançados, 1997, v.11, n. 29, Jan./Abr, São Paulo.

Jakobsen, K. Relações sociais transnacionais e o funcionamento do regime trabalhista internacional. Universidade de São Paulo. 2009. Dissertação (Mestrado em Ciência Política).

Kay, T. NAFTA and the politics of labor transnationalism. Nova Iorque: Cambridge University Press, 2011.

Royo, F.; Dormond, A.; ARIAS, Andrea. 'Sistemas Jurídicos, regímenes de las relaciones individuales y colectivas de trabajo en América Central y México', in Royo, F.; Molina, C. Empleo y relaciones laborales en America Central y Mexico. San José: Confederación Centroamericana de Trabajadores, 2005.

Páez, C. S. Integración económica, empleo y salários en México. Disponível em: http://docencia.izt.uam.mx/egt/. Acesso em 28/mar/2012.

Santos, M. O México como aliado dos EUA no projeto de integração das Américas. Revista Brasileira de Política Internacional, 2007, v. 50, n.2, Brasília, p. 146-161. 
Toledo, E. G. Manufactura y trabajo en México, [2001?]. Disponível em: http://docencia.izt.uam.mx/egt/publicaciones/libros/naftaymercosur/enrique.pdf. Acesso em 28/mar/2012.

United States Trade Representative. North American Free Trade Agreement. Disponível em: http://www.ustr.gov/trade-agreements/free-trade-agreements/north-american-free-trade-agreement-nafta. Acesso em 05/out/2011.

Wise, R. D.; Cypher, J. M. 'The strategic role of mexican labor under nafta: critical perspectives on current economic integration', in Annals of the American Academy of Political and Social Science, v. 610, mar/2007, [s.i.] NAFTA and beyond: alternative perspectives in the study of global trade and development. [s.i.]: Academy of Political and Social Science, mar/2007, p. 120-142. 